\title{
Potentially Avoidable Hospitalization among Long-Term Care Insurance Beneficiaries with Dementia
}

\author{
Jae-Hyun Kim ${ }^{1,2}$, Yunhwan Lee ${ }^{3,4, *}$ \\ 'Department of Health Administration, College of Health Science, Dankook University, Cheonan, Korea \\ ${ }^{2}$ Institute of Health Promotion and Policy, Dankook University, Cheonan, Korea \\ ${ }^{3}$ Department of Preventive Medicine and Public Health, Ajou University School of Medicine, Suwon, Korea \\ ${ }^{4}$ Institute on Aging, Ajou University Medical Center, Suwon, Korea
}

Background: This study investigated the differences in the risk of potentially avoidable hospitalization (PAH) among eligible long-term care insurance (LTCI) beneficiaries with dementia for LTCI services in Korea. Nested case-control study was conducted using the National Health Insurance Service-Senior claim database.

Methods: Cases of individuals who had a PAH incident diagnosis and controls were selected by incidence density sampling and matched to cases based on age, sex, and difficulty of daily living among dementia patients. We conducted incidence density sampling three times by PAH type.

Results: Our main results were presented by conditional logistic regression analysis for the matched case-control studies. Out of the 7,352 eligible LTCI beneficiary patients, there were 1,231 cases (16.7\%) in overall PAH, 132 cases (19.0\%) in acute PAH and 1,114 cases (16.7\%) in chronic PAH categories. In terms of individual risk of overall and chronic PAH, the odds ratios of those who did not receive any services were 1.336 time higher (95\% confidence interval [CI], 1.159-1.540) and 1.280 time higher (95\% CI, 1.103-1.485) compared to those who received home care, respectively. For risk of acute $\mathrm{PAH}$, the odds ratios of those who did receive institutional care were 2.046 time higher (95\% CI, 1.170-3.578) compared to those who received home care.

Conclusion: This study identified the differences in risk of PAH incidents according to the type of LTCI service in the elderly population in Korea. Therefore, it will require substantial effort and strategy from health policy makers to improve care quality.

Keywords: Aging; Dementia; Long-Term Care

Received: October 19, 2018, Revised: November 15, 2018, Accepted: January 17, 2019

${ }^{*}$ Corresponding Author: Yunhwan Lee https://orcid.org/0000-0001-8484-4750

Tel: +82-31-219-5085, Fax: +82-31-219-5084, E-mail: yhlee@ajou.ac.kr 


\section{INTRODUCTION}

An increase in the elderly population in Korea suggests that it will soon become a super-aged society ${ }^{1)}$ which will result in an increase in the prevalence of mental diseases such as dementia, mostly on account of improvements in life expectancy. ${ }^{2)}$ In Korea, until the introduction of long-term care insurance (LTCI), the majority of elderly assistance was provided by informal caregivers (e.g., spouses). The Korean government recently introduced LTCI for people over the age of 65 or under the age of 65 with geriatric or other diseases (e.g., dementia, Parkinson's disease, stroke) in July 2008 to provide physical and social support for the elderly as well as to alleviate the financial burden imposed on caregivers. It covers two categories of service benefits: home care and institutional care. ${ }^{3)}$ Home care refers to LTCI services provided at the older adult's home or in the community and include home visiting care, home bathing, home nursing, day and night care, short-term respite care, among others. Institutional care refers to LTCI services provided in long-term care facilities, such as licensed nursing homes, retirement homes and licensed residential care facilities, ${ }^{4)}$ and include a set of long-term nursing care and rehabilitation services. If an individual is eligible for LTCI benefits they can choose between institutional care and home care.

After choosing between either institutional or home care, service providers play an important role in providing preventive services, continuity of care, and chronic disease management to LTCI beneficiaries. However, complications or potentially avoidable hospitalizations (PAHs) with negative effects at the end-of-life ${ }^{5)}$ may occur in the elderly because of nutritional needs and exposure to infections, ${ }^{6,7)}$ particularly in those with dementia, ${ }^{8)}$ who might require support with functions of daily living and physical activities. ${ }^{9-11)}$

Although the introduction of LTCI provides physical and social support services and also reduces the health care burden for the elderly, the risk of PAH among LTCI beneficiaries with dementia in Korea were unknown. Therefore, this study examines the differences in risk of PAH among LTCI service beneficiaries with dementia.

\section{METHODS}

\section{Study Design and Data Source}

We conducted a retrospective population-based nested case-control study using data from the National Health Insurance Service-Senior (NHIS-Senior) claim database from 2002 to 2013, which is released by the National Health Insurance Service in South Korea. NHIS-Senior was established by stratified systematic random sampling to generate a representative sample in 2002 and was followed up until 2013 (12 years). A representative sample cohort of 558,147 participants was randomly selected, comprising approximately $10 \%$ of the eligible Korean population who were 60 years and above in 2002. The dataset also includes information on NHIS-Senior cohort members who have applied to LTCI, as well as their use of LTCI services, starting from 2008. The data comprises of a nationally representative random sam- ple of 558,147 individuals comprising approximately $10 \%$ of the population aged 60 years and older in 2002. In this study, we conducted incidence density sampling three times to identify each effect of LTCI services on the risk of specific PAH (e.g., overall, acute, and chronic PAH). All databases are linked anonymously according to the Korean laws on privacy using unique encrypted patient codes. Approval from an ethics committee is not required to analyze encrypted claim data. ${ }^{12)}$

\section{Preventable Avoidable Hospitalizations}

The Agency for Healthcare Research and Quality (AHRQ) developed a set of quality measures that required information found in routine hospital administrative data-diagnoses and procedures, along with the patient's age, gender, source of admission, and discharge status data. The AHRQ developed a set of 14 primary care quality measures called "prevention quality indicators" (PQIs), based on the assumption that the hospitalization for several chronic and acute conditions could be prevented with timely and appropriate ambulatory care. These measures were first released in 2000, and have been validated in the United States of America to effect a comparison of the national data. To compute PQIs, we strictly followed the AHRQ Quality Indicators' definitions. Considering the fact that a number of previous studies have already prompted preventable adverse events research by utilizing the AHRQ's PQIs in Korea, comparing the performance should not pose many difficulties in this study. ${ }^{13)}$

\section{Study Population and Identification of Cases}

For the analysis, we included dementia patients diagnosed by doctors who have been eligible for the LTCI program once since July 2008. From the main cohort, we conducted a nested case-control analysis. Cases for this study were identified as hospitalized individuals who had a PAH incident diagnosis based on the (AHRQ) indicators, after entry into the base cohort. ${ }^{14)} \mathrm{PAH}$ was defined as incident cases if the individuals' first records had a hospital admission based on the International Classification of Disease 10th revision (ICD-10), including acute $\mathrm{PAH}$ and chronic $\mathrm{PAH} .{ }^{14)}$ The event date for the cases was set as the date of the first case event. The cases were ascertained at any time during the study duration (July 1, 2008 to December 31, 2013).

\section{Identification of Controls}

In order to achieve unbiased estimates of relative risk, controls were selected by incidence density sampling from the study base, which involved matching each case to a sample of those who are at risk at the time of case occurrence. ${ }^{15,16)}$ Potential controls for the study were individuals who remained in the risk set on the date of $\mathrm{PAH}$ occurrence for the corresponding case during the study period. Controls were matched to cases based on age, sex, and difficulty of daily living for dementia patients. Five controls were randomly selected for each case from the pool of all eligible controls.

\section{Control Variables}

All covariate variables were based on individual and hospital-level co- 
Table 1. General characteristics of participants included for PAH (overall) after matching

\begin{tabular}{|c|c|c|c|c|}
\hline \multirow{2}{*}{ Characteristic } & \multirow{2}{*}{ Total } & \multicolumn{2}{|c|}{ PAH (overall) } & \multirow{2}{*}{ P-value } \\
\hline & & No & Yes & \\
\hline \multicolumn{5}{|l|}{ Individual level } \\
\hline Sex & & & & 0.995 \\
\hline Male & $1,624(22.1)$ & $1,352(83.3)$ & $272(16.8)$ & \\
\hline Female & $5,728(77.9)$ & $4,769(83.3)$ & $959(16.7)$ & \\
\hline Age (y) & & & & 0.999 \\
\hline$\leq 69$ & $177(2.4)$ & $147(83.1)$ & $30(17.0)$ & \\
\hline $70-79$ & $2,880(39.2)$ & 2,398 (83.3) & $482(16.7)$ & \\
\hline $80-89$ & $3,664(49.8)$ & $3,052(83.3)$ & $612(16.7)$ & \\
\hline$\geq 90$ & $631(8.6)$ & $524(83.0)$ & $107(17.0)$ & \\
\hline Difficulty of daily living & & & & 1.000 \\
\hline None & $619(8.4)$ & $515(83.2)$ & $104(16.8)$ & \\
\hline A little & $1,635(22.2)$ & $1,361(83.2)$ & $274(16.8)$ & \\
\hline Difficult & $3,152(42.9)$ & $2,625(83.3)$ & $527(16.7)$ & \\
\hline Very difficult & $1,946(26.5)$ & $1,620(83.3)$ & $326(16.8)$ & \\
\hline Residential region & & & & 0.004 \\
\hline Metropolitan & $965(13.1)$ & $783(81.1)$ & $182(18.9)$ & \\
\hline Urban & $1,532(20.8)$ & $1,245(81.3)$ & $287(18.7)$ & \\
\hline Rural & $4,855(66.0)$ & $4,093(84.3)$ & $762(15.7)$ & \\
\hline Charlson comorbidity index & & & & $<0.0001$ \\
\hline 0 & $2,067(28.1)$ & $1,801(87.1)$ & $266(12.9)$ & \\
\hline 1 & $2,945(40.1)$ & $2,434(82.7)$ & $511(17.4)$ & \\
\hline 2 & $1,506(20.5)$ & $1,227(81.5)$ & $279(18.5)$ & \\
\hline 3 & $550(7.5)$ & $434(78.9)$ & $116(21.1)$ & \\
\hline 4 & $284(3.9)$ & 225 (79.2) & 59 (20.8) & \\
\hline Income & & & & $<0.0001$ \\
\hline Low & $2,846(38.7)$ & 2,301 (80.9) & $545(19.2)$ & \\
\hline Middle & $1,477(20.1)$ & $1,260(85.3)$ & $217(14.7)$ & \\
\hline High & $3,029(41.2)$ & $2,560(84.5)$ & 469 (15.5) & \\
\hline Route of admission & & & & 0.008 \\
\hline Outpatient & $1,853(25.2)$ & $1,571(84.8)$ & $282(15.2)$ & \\
\hline Emergency & $5,272(71.7)$ & $4,375(83.0)$ & $897(17.0)$ & \\
\hline Others & $227(3.1)$ & $175(77.1)$ & $52(22.9)$ & \\
\hline Short memory & & & & 0.652 \\
\hline Normal & $485(6.6)$ & 399 (82.3) & $86(17.7)$ & \\
\hline Slight & $3,024(41.1)$ & 2,509 (83.0) & $515(17.0)$ & \\
\hline Severe & $3,843(52.3)$ & $3,213(83.6)$ & $630(16.4)$ & \\
\hline Long memory & & & & 0.379 \\
\hline Normal & 776 (10.6) & 649 (83.6) & $127(16.4)$ & \\
\hline Slight & $3,541(48.2)$ & $2,926(82.6)$ & $615(17.4)$ & \\
\hline Severe & $3,035(41.3)$ & $2,546(83.9)$ & 489 (16.1) & \\
\hline Place memory & & & & 0.129 \\
\hline Normal & $1,095(14.9)$ & $892(81.5)$ & 203 (18.5) & \\
\hline Slight & $3,277(44.6)$ & 2,723 (83.1) & 554 (16.9) & \\
\hline Severe & $2,980(40.5)$ & $2,506(84.1)$ & $474(15.9)$ & \\
\hline Judgement & & & & 0.754 \\
\hline Normal & $893(12.2)$ & 746 (83.5) & 147 (16.5) & \\
\hline Slight & $3,142(42.7)$ & $2,604(82.9)$ & $538(17.1)$ & \\
\hline Severe & $3,317(45.1)$ & $2,771(83.5)$ & 546 (16.5) & \\
\hline \multicolumn{5}{|l|}{ Hospital level } \\
\hline Hospital type & & & & $<0.0001$ \\
\hline General hospital & $3,363(45.7)$ & 2,879 (85.6) & $484(14.4)$ & \\
\hline Hospital & $1,912(26.0)$ & $1,644(86.0)$ & $268(14.0)$ & \\
\hline Others & $2,077(28.3)$ & $1,598(76.9)$ & $479(23.1)$ & \\
\hline Organization type & & & & 0.163 \\
\hline Public & 447 (6.1) & 370 (82.8) & 77 (17.2) & \\
\hline Corporate & $4,270(58.1)$ & $3,528(82.6)$ & $742(17.4)$ & \\
\hline Private & $2,635(35.8)$ & $2,223(84.4)$ & 412 (15.6) & \\
\hline
\end{tabular}


Table 1. Continued

\begin{tabular}{lccc}
\hline \multicolumn{1}{r}{ Characteristic } & Total & PAH (overall) & Yos \\
\cline { 3 - 3 } & & & No \\
No. of doctors & & & \\
$\leq 49$ & $5,245(71.3)$ & $4,325(82.5)$ & $920(17.5)$ \\
$50-149$ & $606(8.2)$ & $502(82.8)$ & $104(17.2)$ \\
$150-249$ & $386(5.3)$ & $342(88.6)$ & $44(11.4)$ \\
$250-349$ & $416(5.7)$ & $344(82.7)$ & $72(17.3)$ \\
$\geq 350$ & $699(9.5)$ & $608(87.0)$ & $91(13.0)$ \\
Total & $7,352(100.0)$ & $6,121(83.3)$ & $1,231(16.7)$ \\
\hline
\end{tabular}

Values are presented as number (\%).

$\mathrm{PAH}$, potentially avoidable hospitalization.

Table 2. Characteristics of interesting variables by each type of PAH after matching

\begin{tabular}{|c|c|c|c|c|}
\hline \multirow{2}{*}{ Characteristic } & \multirow{2}{*}{ Total } & \multicolumn{2}{|c|}{ РАH } & \multirow{2}{*}{ P-value } \\
\hline & & No & Yes & \\
\hline Type of service (overall) & & & & $<0.0001$ \\
\hline None & $2,679(36.4)$ & $2,167(80.9)$ & $512(19.1)$ & \\
\hline Facility & $1,443(19.6)$ & $1,193(82.7)$ & $250(17.3)$ & \\
\hline Home care & $3,230(43.9)$ & $2,761(85.5)$ & $469(14.5)$ & \\
\hline Total & $7,352(100.0)$ & $6,121(83.3)$ & $1,231(16.7)$ & \\
\hline Type of service (acute) & & & & 0.132 \\
\hline None & 237 (34.2) & $195(82.3)$ & $42(17.7)$ & \\
\hline Facility & $164(23.6)$ & $124(75.6)$ & $40(24.4)$ & \\
\hline Home care & $293(42.2)$ & $243(82.9)$ & $50(17.1)$ & \\
\hline Total & $694(100.0)$ & $562(81.0)$ & $132(19.0)$ & \\
\hline Type of service (chronic) & & & & $<0.0001$ \\
\hline None & $2,467(37.1)$ & 1,994 (80.8) & 473 (19.2) & \\
\hline Facility & $1,260(18.9)$ & $1,043(82.8)$ & 217 (17.2) & \\
\hline Home care & $2,930(44.0)$ & $2,506(85.5)$ & $424(14.5)$ & \\
\hline Total & $6,657(100.0)$ & $5,543(83.3)$ & $1,114(16.7)$ & \\
\hline
\end{tabular}

Values are presented as number (\%).

$\mathrm{PAH}$, potentially avoidable hospitalization.

variates. Individual-level covariates included residential region, the Charlson comorbidity index (CCI), income, route of admission, shortterm and long-term memory, place memory, and judgement as diagnosed by doctor. Residential regions were categorized into metropoli$\tan$ (Seoul), urban (Daejeon, Daegu, Busan, Incheon, Kwangju, or Ulsan), and rural (otherwise). The CCI was grouped as scores of $0,1,2,3$, and over 4. Income was distributed in deciles and categorized into three groups: low ( $\leq 3)$, middle (4-7) or high (8-10). Route of admission type was categorized into three groups: emergency, outpatients, and others, which includes the decision of admission by doctors. Shortterm memory, long-term memory, place memory, and judgement were categorized into three groups: normal, slight, and severe. As a hospital-level variable, hospital type was categorized into three groups: general hospital, hospital, and others including clinics. The organization types were categorized into three groups: public, corporate, and private. Number of doctors was categorized into five groups: $\leq 49$, 50-149, 150-249, 250-349, and $\geq 350$.

\section{Statistical Analysis}

In this study, analyses were conducted with SAS statistical software ver. 9.4 (SAS Institute Inc., Cary, NC, USA), using conditional logistic regression methods for matched case-controls studies. We calculated odds ratios (ORs) with $95 \%$ confidence intervals (CIs) for each of the exposure variables. All the estimated odds ratios were conditional on the matching factors. Differences in the covariate distribution between cases and controls were evaluated using chi-square tests for categorical variables. All statistical tests were two-tailed, with the null hypothesis of no difference being rejected if $\mathrm{P}<0.05$.

\section{RESULTS}

Out of the 7,352 eligible LTCI beneficiary patients, there were 1,231 cases (16.7\%) with a diagnosis of overall PAH. Approximately $39.2 \%$ of those were aged $70-79$ years, $49.8 \%$ were aged 49.8 years, and $8.6 \%$ were aged 90 years or over at the index date. Of the total participants, $77.9 \%(\mathrm{n}=5,728)$ were female (Table 1$)$.

Table 2 shows the general characteristics by specific PAH from inci- 
Table 3. Adjusted effect of all variable on PAH (overall)

\begin{tabular}{|c|c|}
\hline Variable & PAH (overall) \\
\hline \multicolumn{2}{|l|}{ Type of service } \\
\hline None & $1.336(1.159-1.540)$ \\
\hline Facility & $1.191(1.000-1.420)$ \\
\hline Home care & 1.000 \\
\hline \multicolumn{2}{|l|}{ Individual level } \\
\hline \multicolumn{2}{|l|}{ Residential region } \\
\hline Metropolitan & 1.425 (1.179-1.723) \\
\hline Urban & $1.258(1.076-1.471)$ \\
\hline Rural & 1.000 \\
\hline \multicolumn{2}{|c|}{ Charlson comorbidity index } \\
\hline 0 & 1.000 \\
\hline 1 & 1.409 (1.196-1.660) \\
\hline 2 & $1.532(1.269-1.849)$ \\
\hline 3 & $1.753(1.363-2.255)$ \\
\hline 4 & $1.843(1.336-2.542)$ \\
\hline \multicolumn{2}{|l|}{ Income } \\
\hline Low & $1.288(1.119-1.484)$ \\
\hline Middle & $0.975(0.816-1.166)$ \\
\hline High & 1.000 \\
\hline \multicolumn{2}{|l|}{ Route of admission } \\
\hline Outpatient & 1.000 \\
\hline Emergency & $0.896(0.754-1.064)$ \\
\hline Others & $1.107(0.765-1.602)$ \\
\hline \multicolumn{2}{|l|}{ Short-term memory } \\
\hline Normal & 1.000 \\
\hline Slight & $0.872(0.619-1.227)$ \\
\hline Severe & $0.878(0.602-1.282)$ \\
\hline \multicolumn{2}{|l|}{ Long-term memory } \\
\hline Normal & 1.000 \\
\hline Slight & $1.249(0.910-1.715)$ \\
\hline Severe & $1.158(0.804-1.669)$ \\
\hline \multicolumn{2}{|l|}{ Place memory } \\
\hline Normal & 1.000 \\
\hline Slight & $0.656(0.495-0.869)$ \\
\hline Severe & $0.552(0.390-0.782)$ \\
\hline \multicolumn{2}{|l|}{ Judgement } \\
\hline Normal & 1.000 \\
\hline Slight & $1.422(1.026-1.973)$ \\
\hline Severe & $1.613(1.094-2.377)$ \\
\hline \multicolumn{2}{|l|}{ Hospital level } \\
\hline \multicolumn{2}{|l|}{ Hospital type } \\
\hline General hospital & 1.000 \\
\hline Hospital & $1.118(0.899-1.390)$ \\
\hline Others & 2.090 (1.694-2.579) \\
\hline \multicolumn{2}{|l|}{ Organization type } \\
\hline Public & $1.458(1.090-1.951)$ \\
\hline Corporate & 1.449 (1.244-1.689) \\
\hline Private & 1.000 \\
\hline \multicolumn{2}{|l|}{ No. of doctor } \\
\hline$\leq 49$ & $1.237(0.918-1.667)$ \\
\hline $50-149$ & $1.466(1.067-2.015)$ \\
\hline $150-249$ & $0.846(0.573-1.249)$ \\
\hline $250-349$ & 1.415 (1.006-1.992) \\
\hline$\geq 350$ & 1.000 \\
\hline
\end{tabular}

Values are presented as odds ratio (95\% confidence interval).

$\mathrm{PAH}$, potentially avoidable hospitalization.
Table 4. Adjusted effect of type of service for type of PAH

\begin{tabular}{lc}
\hline \multicolumn{1}{c}{ Variable } & PAH \\
\hline Type of service (acute) & \\
None & $1.299(0.791-2.132)$ \\
Facility & $\mathbf{2 . 0 4 6}(\mathbf{1 . 1 7 0 - 3 . 5 7 8 )}$ \\
Home care & 1.000 \\
Type of service (chronic) & \\
None & $1.280(1.103-1.485)$ \\
Facility & $\mathbf{1 . 1 8 2 ( 0 . 9 7 9 - 1 . 4 2 7 )}$ \\
Home care & 1.000
\end{tabular}

Values are presented as odds ratio ( $95 \%$ confidence interval). Bold type is considered statistically significant.

$\mathrm{PAH}$, potentially avoidable hospitalization.

dence density sampling. In the overall and chronic PAH cases, those who did not receive any service exhibited high rates (19.1\% and $19.2 \%$, respectively). In acute PAH cases, those who did receive institutional care exhibited had high rates of acute PAH (24.4\%) (Table 2).

Table 3 presents the results of the conditional logistic regression for overall PAH. Increased risks of PAH were associated with metropolitan areas, those with complex diseases, low income, poor judgement ability, those who were admitted to small hospitals, and those admitted to public hospitals compared to those in rural areas, those with no complex diseases, high income, normal judgement ability, those admitted to general hospitals and those admitted to private hospitals, respectively. In terms of risk of PAH by type of LTCI services received, the OR of those who did not receive any services were 1.336 time higher (95\% CI, 1.159-1.540) when it came to the risk of overall PAH compared to those who received home care (Table 3 ).

Table 4 shows the effect of the type of LTCI services for each acute and chronic PAH, respectively. The OR of those who did receive institutional care were 2.046 time higher (95\% CI, 1.170-3.578) for risk of acute PAH compared to those who received home care. For risk of chronic PAH, the OR of those who did not receive any services were 1.280 time higher (95\% CI, 1.103-1.485) compared to those who received home care (Table 4 ).

\section{DISCUSSION}

To our knowledge, this is the first study to examine risk of PAH incidents for LTCI service beneficiaries with dementia by analyzing the 2002-2013 database of the large representative and longitudinal national cohort sample in Korea. The major findings of our study are as follows: Although our results assume that utilization of services by the LTCI beneficiaries puts older adults in a situation where the risk of $\mathrm{PAH}$ are reduced compared to those not using the LTCI services, it is recommended that LTCI beneficiaries with dementia continue homecare as long as possible to prevent the risk of PAH. In addition, our results also showed that older adults being at a higher risk of developing conditions associated with acute $\mathrm{PAH}$ result from institutional care rather than home-care.

There may be several potential mechanisms in terms of the risk of 
PAH incidence according to LTCI services; first, home care can prevent a decline in the physical state of older adults ${ }^{17)}$ because those with a decline in physical state appear particularly vulnerable to PAH for conditions that are typically manageable. ${ }^{18)}$ Second, because LTCI programs were not originally designed to provide the clinical support that can prevent some hospitalizations in institutional care settings, physicians are generally not on-site and the majority of care is provided by nurses and personal support workers. In addition, since LTCI beneficiaries are probably more medically unstable and tend to have extensive multiple chronic conditions, making their cases clinically complex, most institutional care which is of a for-profit nature may provide a lower quality of care to reduce costs and generate profit maximization. ${ }^{19)}$ Finally, institutionalized individuals are often under closer observation by trained professionals or nurses and hospital transfers can be arranged more frequently for them compared to those in homecare or those who do not receive any LTCI service. Previous studies showed that a higher frequency of physician visits and hospital care for chronically ill patients was associated with worse outcomes that are avoidable, suggesting that overuse of services was leading to harm, possibly because greater use of hospital and specialist care exposes the population to greater risk of complications. ${ }^{20,21)}$ Ideally, the overall goals of LTCI services should focus on delaying deterioration in cognition and physical function and managing behavioral symptoms effectively. However, a decrease in PAH risk for LTCI beneficiaries continues to be very challenging, particularly since LTCI service providers have no clear incentives not to hospitalize. When older adults are at end-of-life, institutional care may choose to hospitalize patients to avoid potential litigation. ${ }^{22)}$ Thus, reducing PAH rates will require extensive efforts by policy makers to make substantial investments in facility infrastructure and/or incentives for facilities to improve the quality of care. Thus, improvement in quality of care and educational activities to improve the recognition and evaluation, as well as early management of these conditions may help to reduce these hospitalizations. ${ }^{23)}$ From an economic perspective, PAH of individuals with dementia is far more costly than the care of older adults in general. ${ }^{24-26)}$ Therefore, even a modest reduction in the risk of PAH among those with dementia would result in substantial savings in regards to the social, psychological, and financial burden on their family or caregivers, and society. ${ }^{9)}$

The present findings support the difference in risks of PAH incidence among LTCI service beneficiaries in older adults suffering from dementia. Further work on the LTCI data identifying the amount and type of each service will help future planning and supply of LTCI services. Further analysis to better understand what these changes mean for individuals and from the perspective of the family will also be beneficial.

Although these findings provide important insights and healthcare policy implications for addressing the issue of PAH among LTCI beneficiaries, there are several limitations to this study that may affect the generalizability of the findings. First, although the nested case-control study is increasingly used to study causal relationships, the possibility that results were biased by reverse causality cannot be ruled out. ${ }^{27)}$ Second, in this study, PAHs were identified by conditions considered to be potentially preventable. However, not all hospitalizations identified by diagnoses are avoidable for everyone or in all circumstances. This is because diagnoses alone by ICD-code cannot account for the severity of disease or the many other factors that may contribute to the decision to hospitalize. Although we attempted to control for severity through CCI, decisions to hospitalize should be made based on clinical judgment and complete information about patients' clinical condition. Therefore, without additional clinical information, administrative claim data used can only partially distinguish between PAHs and other hospitalizations.

In conclusion, to our knowledge this study is the first of its kind to identify the difference in risks of PAH incidence by type of LTCI services among the elderly population in Korea. The results showed that risks of PAH incidence were more likely to happen with beneficiaries who do not receive any LTCI services other than home-care. Therefore, both policy makers and LTCI service providers will require substantial efforts to improve the quality of care that may prevent $\mathrm{PAH}$ incidents among older adults.

\section{CONFLICT OF INTEREST}

No potential conflict of interest relevant to this article was reported.

\section{ORCID}

Jae-Hyun Kim: https://orcid.org/0000-0002-3531-489X

Yunhwan Lee: https://orcid.org/0000-0001-8484-4750

\section{REFERENCES}

1. Ministry of Health and Welfare. Ministry of Health and Welfare statistical year book 2013. Seoul: Ministry of Health and Welfare; 2013.

2. Sosa AL, Albanese E, Stephan BC, Dewey M, Acosta D, Ferri CP, et al. Prevalence, distribution, and impact of mild cognitive impairment in Latin America, China, and India: a 10/66 population-based study. PLoS Med 2012;9:e1001170.

3. Kim H, Kwon S, Yoon NH, Hyun KR. Utilization of long-term care services under the public long-term care insurance program in Korea: Implications of a subsidy policy. Health Policy 2013;111:166-74.

4. Lee S. Dementia strategy Korea. Int J Geriatr Psychiatry 2010;25:931-2.

5. Vohra JU, Brazil K, Hanna S, Abelson J. Family perceptions of end-oflife care in long-term care facilities. J Palliat Care 2004;20:297-302.

6. Gillick M, Steel K. Referral of patients from long-term to acute-care facilities. J Am Geriatr Soc 1983;31:74-8.

7. Gill TM, Allore HG, Holford TR, Guo Z. Hospitalization, restricted activity, and the development of disability among older persons. JAMA 2004;292:2115-24.

8. Bo M, Martini B, Ruatta C, Massaia M, Ricauda NA, Varetto A, et al. Geriatric ward hospitalization reduced incidence delirium among older medical inpatients. Am J Geriatr Psychiatry 2009;17:760-8. 
9. Gitlin LN, Winter L, Dennis MP, Hodgson N, Hauck WW. Targeting and managing behavioral symptoms in individuals with dementia: a randomized trial of a nonpharmacological intervention. J Am Geriatr Soc 2010;58:1465-74.

10. Ko SH, Lee MC, Baumann SL. Reducing the burden of dementia in Korea. Nurs Sci Q 2007;20:178-82.

11. Morgan RO, Sail KR, Snow AL, Davila JA, Fouladi NN, Kunik ME. Modeling causes of aggressive behavior in patients with dementia. Gerontologist 2013;53:738-47.

12. Lee J, Lee JS, Park SH, Shin SA, Kim K. Cohort profile: the National Health Insurance Service-National Sample Cohort (NHIS-NSC), South Korea. Int J Epidemiol 2017;46:e15.

13. Kim NS, Hwang J, Park SH, Chae SM, Choi YK. Feasibility of using administrative data to compare healthcare-associated infection performance. Health Soc Welf Rev 2017;37:495-518.

14. Agency for Healthcare Research and Quality. AHRQ quality indicators: guide to prevention quality indicators: hospital admission for ambulatory care sensitive conditions. Rockville (MD): Agency for Healthcare Research and Quality; 2001.

15. Flanders WD, Louv WC. The exposure odds ratio in nested case-control studies with competing risks. Am J Epidemiol 1986;124:684-92.

16. Richardson DB. An incidence density sampling program for nested case-control analyses. Occup Environ Med 2004;61:e59.

17. Stuck AE, Aronow HU, Steiner A, Alessi CA, Bula CJ, Gold MN, et al. A trial of annual in-home comprehensive geriatric assessments for elderly people living in the community. N Engl J Med 1995;333:1184-9.

18. Schussler-Fiorenza Rose SM, Stineman MG, Pan Q, Bogner H, Kurichi JE, et al. Potentially avoidable hospitalizations among people at different activity of daily living limitation stages. Health Serv Res 2017;52: 132-55.
19. Hillmer MP, Wodchis WP, Gill SS, Anderson GM, Rochon PA. Nursing home profit status and quality of care: is there any evidence of an association? Med Care Res Rev 2005;62:139-66.

20. Fisher ES, Wennberg DE, Stukel TA, Gottlieb DJ, Lucas FL, Pinder EL. The implications of regional variations in Medicare spending: part 1: the content, quality, and accessibility of care. Ann Intern Med 2003; 138:273-87.

21. Creditor MC. Hazards of hospitalization of the elderly. Ann Intern Med 1993;118:219-23.

22. Stevenson DG, Studdert DM. The rise of nursing home litigation: findings from a national survey of attorneys. Health Aff (Millwood) 2003; 22:219-29.

23. Ouslander JG, Perloe M, Givens JH, Kluge L, Rutland T, Lamb G. Reducing potentially avoidable hospitalizations of nursing home residents: results of a pilot quality improvement project. J Am Med Dir Assoc 2009;10:644-52.

24. Sands LP, Xu H, Weiner M, Rosenman MB, Craig BA, Thomas J 3rd. Comparison of resource utilization for Medicaid dementia patients using nursing homes versus home and community based waivers for long-term care. Med Care 2008;46:449-53.

25. Boockvar KS, Gruber-Baldini AL, Burton L, Zimmerman S, May C, Magaziner J. Outcomes of infection in nursing home residents with and without early hospital transfer. J Am Geriatr Soc 2005;53:590-6.

26. Boockvar KS, Gruber-Baldini AL, Stuart B, Zimmerman S, Magaziner J. Medicare expenditures for nursing home residents triaged to nursing home or hospital for acute infection. J Am Geriatr Soc 2008;56:120612.

27. Essebag V, Genest J Jr, Suissa S, Pilote L. The nested case-control study in cardiology. Am Heart J 2003;146:581-90. 